\title{
QFD ESTENDIDO EM AMBIENTE DE GERENCIAMENTO DE INFORMAÇÕES PARA ENSINO DISTÂNCIA
}

\section{EXTENDED QFD IN TH FIELD OF MANAGEMENT OF INFORMATIONS TO TEACHING DISTANCE}

\author{
José Augusto Fabri \\ Doutorando \\ Universidade de São Paulo \\ Departamento de Engenharia de Produção \\ Av. Prof ${ }^{\circ}$ Almeida Prado n ${ }^{\circ} 5312^{\circ}$ Andar CEP: 05508-900 - Cidade Universitária - São Paulo \\ Tel.: (11) 3814-7366 \\ Professor da \\ Fundação Educacional do Município de Assis - Centro de Pesquisas em Informática \\ Av. Getúlio Vargas, 1200 - Assis SP - Brasil. \\ fabri@femanet.com.br
}

\section{Marly Monteiro de Carvalho}

Professora

Universidade de São Paulo

Departamento de Engenharia de Produção

Av. Prof ${ }^{\mathrm{o}}$ Almeida Prado ${ }^{\mathrm{o}} 5312^{\circ}$ Andar CEP: 05508-900 - Cidade Universitária - São Paulo Tel.: (11) 3814-7366

marlymc@usp.br

\section{RESUMO}

O crescimento de projetos que buscam soluções viáveis na área de qualidade em Ensino a Distância (EAD) é uma realidade que deve ser considerada. Por outro lado, existe o questionamento em relação aos resultados na implementação de tais projetos, não apenas em termos de viabilidade econômica, mas também quanto ao grau de atendimento aos requisitos dos clientes. O Quality Function Deployment (QFD), em especial a primeira matriz - a Casa da Qualidade (House of Quality-HoQ) permite traduzir as demandas do consumidor em metas de projeto e pontos prioritário para a definição do escopo. Como o QFD será utilizado 
em um ambiente dinâmico no qual o conceito e tecnologia a serem utilizados no projeto ainda prescinde de definição, o QFD Estendido (EQFD), que integra o QFD convencional ao processo de seleção de conceitos, foi utilizado. A pesquisa foi desenvolvida através de um estudo de caso em uma instituição de ensino superior, na qual foi desenvolvido um processo de seleção de conceitos, tanto no concerne à tecnologia como às necessidades do usuário, de uma nova aplicação de EAD.

Palavras Chaves: QFD, E-QFD e Tecnologia em Ensino a Distância.

\begin{abstract}
The growth of projects that look for viable solutions with quality int the area Teaching Distance is a reality that should be considered. On the other hand, exist many questions about the results of this projects, for example: viability economic, quality degree to the customers' requirements. The Quality Function Deployment (QFD), especially the first matrix - House of the Quality (HoQ), allows to translate the consumer's demands in the definition of the scope of a project. As QFD will be used in a dynamic environment in which the concept and technology used in the project still wasn't defined. The Extended QFD (EQFD) integrates the QFD to the process of concepts selection will be used. The research was developed through a case study in a University, in which a process of concepts selection was developed in relation to the tecnology and users requirements.
\end{abstract}

Key words: QFD, E-QFD and Technology in Teaching Distance.

\title{
1. INTRODUÇÃO
}

O crescimento de projetos que buscam soluções viáveis na área de qualidade em Ensino a Distância (EAD), em que professor e aluno estejam separados no tempo e no espaço, é uma realidade que deve ser considerada (Chaves, 1999). Por outro lado, existe o questionamento em relação aos resultados na implementação de tais projetos, não apenas em termos de viabilidade econômica, mas também quanto à necessidade de algum modelo que expresse o grau de qualidade tecnológica dos mesmos.

O Quality Function Deployment (QFD) é um método de desenvolvimento de projeto dirigido para a satisfação do consumidor, que traduz as demandas do consumidor em metas de projeto e pontos prioritário para a garantia da qualidade a serem utilizados no estágio de produção (Akao, 1990). O QFD Estendido (EQFD) integra o modelo proposto no QFD ao processo de seleção de conceitos definido por Stuart Pugh (Pugh, 1996; Carvalho, 1997). Este 
modelo se aplica ao desenvolvimento de produtos complexos e dinâmicos, pois prioriza o detalhamento e a inovação de conceitos, que o QFD tradicional não consegue capturar. A união do EQFD a projetos que busquem soluções em EAD pode resultar em uma importante arma para a busca de qualidade tecnológica.

O objetivo desse trabalho é apresentar a primeira matriz do QFD, denominada por Hauser; (Clausing, 1988), como Casa da Qualidade (HoQ), para a área de tecnologia de um ambiente de ensino a distância. Como este trabalho aplica-se a priorização de requisitos de aplicações para EAD, optou-se pelo modelo de QFD estendido, uma vez que se acredita tratar de um desenvolvimento dinâmico, cujo conceito ainda deve ser gerado (Pugh et al., 1996).

O trabalho foca o processo de seleção de conceitos de um sistema para EAD, utilizando a abordagem metodológica de estudo de caso. O modelo teórico para análise baseia-se no uso do EQFD balizado pelas diretrizes de gestão de escopo propostas pelo Project Management Body of Knowledge - PMBoK do Project Management Institute - PMI (PMI, 2004).

Para PMI (2004) escopo refere-se ao trabalho a ser realizado no âmbito do projeto, tanto no que concerne ao gerenciamento do escopo do projeto como ao gerenciamento de escopo do produto, sendo que estes variam conforme as áreas de aplicação. Os processos da gestão do escopo são: planejamento do escopo; definição do escopo; criação da WBS; verificação do escopo; e controle das alterações do escopo.

Esse texto foi desenvolvido em 4 fases: 1 - utilização da EQFD na seleção dos conceitos relevantes para área de EAD; 2 - definição (público alvo do curso e o time de gerenciamento de projeto); 3 - levantamento dos requisitos tecnológicos; 4 - classificação dos requisitos para construção da "Casa de Qualidade", segundo peso relativo proposto no QFD; 
elaboração de um documento que expresse as recomendações necessárias para o desenvolvimento de ambientes de gerenciamento de informações para EAD.

\section{FORMALIZAÇÃO DOS CONCEITOS DE EAD}

As evoluções tecnológicas vêm provocando grandes transformações na área acadêmica e nas empresas (Rosenberg, 2002). Entre elas, a informática vem promovendo uma revolução no modo e na velocidade com que as pessoas têm acesso às informações. A Internet é uma realidade presente no contexto de alunos e professores. Deste modo o computador é considerado uma ferramenta importante no aprendizado e atualização dos mesmos.

Outra área que faz parte destas evoluções é o ensino a distância. No sentido fundamental da expressão, Ensino a Distância (EAD) é algo bastante antigo, é o ensino que ocorre quando o professor, instrutor ou tutor e o aluno estão separados no tempo e/ou no espaço físico, psicológico, social, cultural, econômico e filosófico.

Para o MEC (1998), Educação a Distância (termo esse utilizado pelo MEC, porém os autores desse trabalho encaram que o conceito de Educação é algo inerente à formação familiar do indivíduo, fato que motiva os autores a utilizarem o termo ensino) é uma forma de educação que possibilita o auto-aprendizado com a mediação de recursos didáticos sistematizados, veiculados por meios de comunicação, podendo fazer uso de diversas mídias.

Segundo Chaves (1999), para que possa existir EAD é necessário que ocorra a intervenção de alguma tecnologia. A primeira tecnologia que permitiu o EAD foi a escrita, e posteriormente, a tecnologia tipográfica ampliou o alcance do EAD. Recentemente, as tecnologias de comunicação e telecomunicações, especialmente, em sua versão digital, ampliaram ainda mais o alcance e as possibilidades de EAD.

Conforme apresentado em Chaves (1999), o computador permitiu que textos fossem enviados com facilidade a localidades remotas, ou fossem buscados com facilidade nestas 
localidades. O primeiro computador foi revelado ao mundo em 1946, mas foi só depois do surgimento e do uso constante de microcomputadores (final de 1977) que este começou a ser visto como tecnologia educacional. A Internet, embora tenha sido criada em 1969, só "explodiu" no mercado nos últimos quinze anos, quando foi aberta para uso comercial, pois antes atendia apenas a comunidade acadêmica.

Desta forma, o correio eletrônico também permitiu que as pessoas se comunicassem assincronamente com extrema rapidez. Mais recentemente, o aparecimento de chats (batepapos) permitiu a comunicação síncrona entre pessoas. E, mais importante, a Web permitiu não só que fosse agilizado o acesso a documentos textuais, mas também a gráficos, fotografias, sons e vídeos. Além disso, o acesso a todo esse material pode ser feito de forma não-linear e interativa, usando a tecnologia de hipertexto.

Atualmente, os termos ensino e tecnologia estão intimamente ligados, assim, pode-se afirmar que a aplicação de fatores tecnológicos contribuem para a mudança do atual processo de ensino e aprendizagem. A tecnologia computacional foi fundamental para a consolidação da área de ensino a distância, principalmente, quanto ao sincronismo e interatividade, ampliando a influência da informática na educação (Rosenberg, 2002).

\section{ASPECTO DE QUALIDADE EM ENSINO A DISTÂNCIA}

Metrificar qualidade em EAD não é algo simples, pois existem diversos fatores que influenciam nos aspectos de qualidade de um ambiente de gerenciamento para EAD. Um ponto inicial pode ser declarado como fator de qualidade. Um ambiente de gerenciamento ou aplicação para EAD deve satisfazer as necessidades implícitas e explícitas de alunos e professores

A questão neste momento passa a ser: quais são estas necessidades? 
O Ministério de Educação e Cultura (MEC-Brasil) apresenta alguns indicadores de qualidade para os cursos a distância (MEC, 2002): desenho do projeto: a identidade do ensino a distância; formação de uma equipe profissional multidisciplinar; comunicação e interatividade entre professor e aluno; qualidade nos recursos educacionais; infra-estrutura de apoio; avaliação de qualidade contínua e abrangente; convênios e parcerias; edital de informação sobre o curso de graduação a distância; custo de implementação e manutenção.

Verifica-se que os itens de qualidade do MEC possuem uma descrição superficial e não possuem parâmetros para que equipes de gerenciamento de projetos implementem qualidade em aplicações para EAD. Por exemplo, o item: necessidade de uma equipe profissional multidisciplinar. Este item deixa no ar a pergunta: Quais são os membros que compõem esta equipe?

Existem vários esforços na comunidade científica para indicar padrões ou características de qualidade para aplicações de EAD. A seguir discute-se alguns destes esforços.

Para o desenvolvimento de uma aplicação para EAD é necessário a estruturação prévia de um projeto e este deve ser gerenciado com qualidade. Segundo descrito no PMI (2004), para o gerenciamento de projetos é necessário possuir um escopo bem definido o que compreende as seguintes atividades: planejamento do escopo, detalhamento do escopo, verificação do escopo e controle de mudanças do escopo; gerência do tempo de projeto: definição das atividades, seqüenciamento das atividades, estimativa da duração das atividades, desenvolvimento de um cronograma e controle do cronograma; gerência do custo do projeto: planejamento dos recursos, estimativas dos custos, orçamento dos custos e controle dos custos; gerência da qualidade do projeto: planejamento da qualidade, garantia da qualidade e controle da qualidade; gerência dos recursos humanos do projeto: planejamento organizacional, montagem da equipe e desenvolvimento da equipe; gerenciamento das 
comunicações do projeto: planejamento das comunicações, distribuição das informações, relato de desempenho e encerramento administrativo; gerência dos riscos de projeto: identificação dos riscos, análise qualitativa dos riscos, desenvolvimento de resposta a riscos e controle e monitoração de riscos; gerenciamento das aquisições do projeto: planejamento das aquisições, preparação das aquisições, obtenção de propostas, seleção de fornecedores, administração dos contratos e encerramento dos contratos.

É importante citar que o PMI (2004) não é uma receita para o gerenciamento de projetos, ele é caracterizado como um conjunto de conhecimento da área de gerência de projetos. Portanto, sua aplicação deve ser balizada segundo as necessidades peculiares de cada projeto. Vários conceitos encontrados no PMI (2004) aplicam-se ao gerenciamento de projetos nas aplicações de EAD. A definição de escopo, por exemplo: é necessário definir para quem a aplicação é voltada; o que professores e alunos podem ou não fazer com a aplicação; o quanto à aplicação deve mudar para que permaneça interessante; como dar aos professores e alunos o poder para personalizar a aplicação e, principalmente, deve-se ter em mente que todas as etapas do processo de ensino e aprendizagem, professores e alunos utilizam produtos ou aplicações que os façam sentir-se bem.

Definido o escopo da aplicação, faz-se necessário levantar e validar os requisitos para o seu desenvolvimento, neste momento a voz do cliente (professor e aluno) torna-se muito importante para o sucesso de uma aplicação para EAD. Existem diversas formas de levantar requisitos entre elas pode-se citar: entrevistas com o cliente, aplicação de questionários, etc (Pressman, 1997).

Em um projeto para o desenvolvimento de uma aplicação para EAD a definição da equipe de projeto é um fator crítico na busca da qualidade, a necessidade de uma equipe multidisciplinar se faz necessária em todas as fazes de ciclo de vida do projeto. Uma equipe multidisciplinar para um projeto de EAD deve ser composta de: professores: pessoas 
responsáveis por criar os cursos, aulas, etc; especialista didático-pedagógico em EAD: profissional com formação pedagógica e que possui experiência projeto de EAD; engenheiro de software: profissional que insere, modela a informação no ambiente (software, por exemplo) em questão; psicólogo: profissional que tenta resolver problemas sociais, culturais entre os participantes do EAD; arquiteto da informação: profissional que constrói o curso no ambiente, este profissional seria comparado a um web-design com noções de arquitetura e semiótica; e por fim aluno que deve aprender com satisfação.

Definidos o escopo, requisitos e a equipe de projeto, pode-se fazer uma estimativa dos custos do projeto.

O gerenciamento da qualidade de uma aplicação de EAD está inerente a todas as fases do ciclo de vida do projeto. Na definição da equipe, por exemplo: o gerente de projeto deve estar atento às habilidades de cada membro da equipe. $\mathrm{O}$ treinamento de membros da equipe deve ser contemplado para evitar futuras falhas de especificação da aplicação. No gerenciamento das aquisições, os produtos necessários para que um ambiente de EAD possa funcionar devem possuir um certo padrão de qualidade, isto implica que os fornecedores destes produtos também possuam um certo grau de qualidade.

Outros requisitos em relação a qualidade de aplicações de EAD poderiam ser discutidos neste trabalho, porém o objetivo central do mesmo não é propor um padrão de qualidade para as aplicações em EAD e sim expressar a conversão dos requisitos do consumidor em características de qualidade para uma aplicação de EAD.

Para expressar a conversão dos requisitos do consumidor este trabalho utiliza o modelo QFD (Akao, 1990; Cohen, 1995), mais especificamente o modelo estendido EQFD (Pugh, 1997).

\section{DESDOBRAMENTO DA FUNÇÃO DA QUALIDADE (QFD) E O QFD ESTENDIDO}


Conforme definido anteriormente, atender às necessidades implícitas e explícitas do cliente é um fator crucial para a obtenção de qualidade. Para alcançar este objetivo uma das ferramentas que pode ser utilizada é o QFD, tal ferramenta busca incorporar ao processo de desenvolvimento de produtos ou serviços, o perfeito atendimento das necessidades explícitas e implícitas dos clientes.

O QFD foi definido por Yoji Akao em 1966. Em 1972 seu potencial tinha sido demonstrado ao se implementar nos estaleiros da Mitsubishi Haevy Industries em Kobe.

De acordo com Akao (1990), o QFD é a conversão dos requisitos do consumidor em características de qualidade de produto e o desenvolvimento da qualidade de projeto para o produto acabado, por meio de desdobramentos das relações entre os requisitos do consumidor e as características do produto. Tais desdobramentos iniciam-se com cada mecanismo e se estendem para cada componente ou processo. A qualidade global do produto será formada através desta série de relações.

A estrutura do QFD é matricial, onde a primeira dessas matrizes é a matriz da qualidade que expressa a qualidade demandada pelo cliente com os requisitos técnicos necessários para atender a essa qualidade exigida (Cohen, 1995). As matrizes subseqüentes dependerão dos objetivos que a aplicação deve alcançar.

O QFD é um modelo que pode ser empregado durante todo o processo de desenvolvimento de um produto ou serviço, seu objetivo é auxiliar a equipe de desenvolvimento a incorporar no projeto as necessidades reais dos clientes. Com isso, por meio de um conjunto de matrizes parte-se dos requisitos expostos pelos clientes e realiza-se um processo de desdobramento transformando-os em especificações do produto ou serviço. As matrizes servem de apoio para a equipe de desenvolvimento orientando o trabalho, permitindo avaliações e priorizando os requisitos e características e, ao final, será uma importante fonte de informações para execução do projeto (Carvalho 1997). 
Alguns benefícios da aplicação do QFD podem ser citados (Carvalho 1997): aumento na satisfação dos clientes; incremento da qualidade e conhecimento das necessidades dos clientes; melhoria no desempenho do produto; redução do número de chamadas de garantida; transmissão de conhecimento e curva de aprendizado mais rápida; melhoria na documentação (registro de informações); redução de custos e de tempo de desenvolvimento; identificação de problemas latentes no projeto; menor número de mudanças de projeto; menos problemas de campo; interpretações convergentes das especificações; aumento do comprometimento dos membros da equipe com as decisões tomadas.

\section{QFD Estendido}

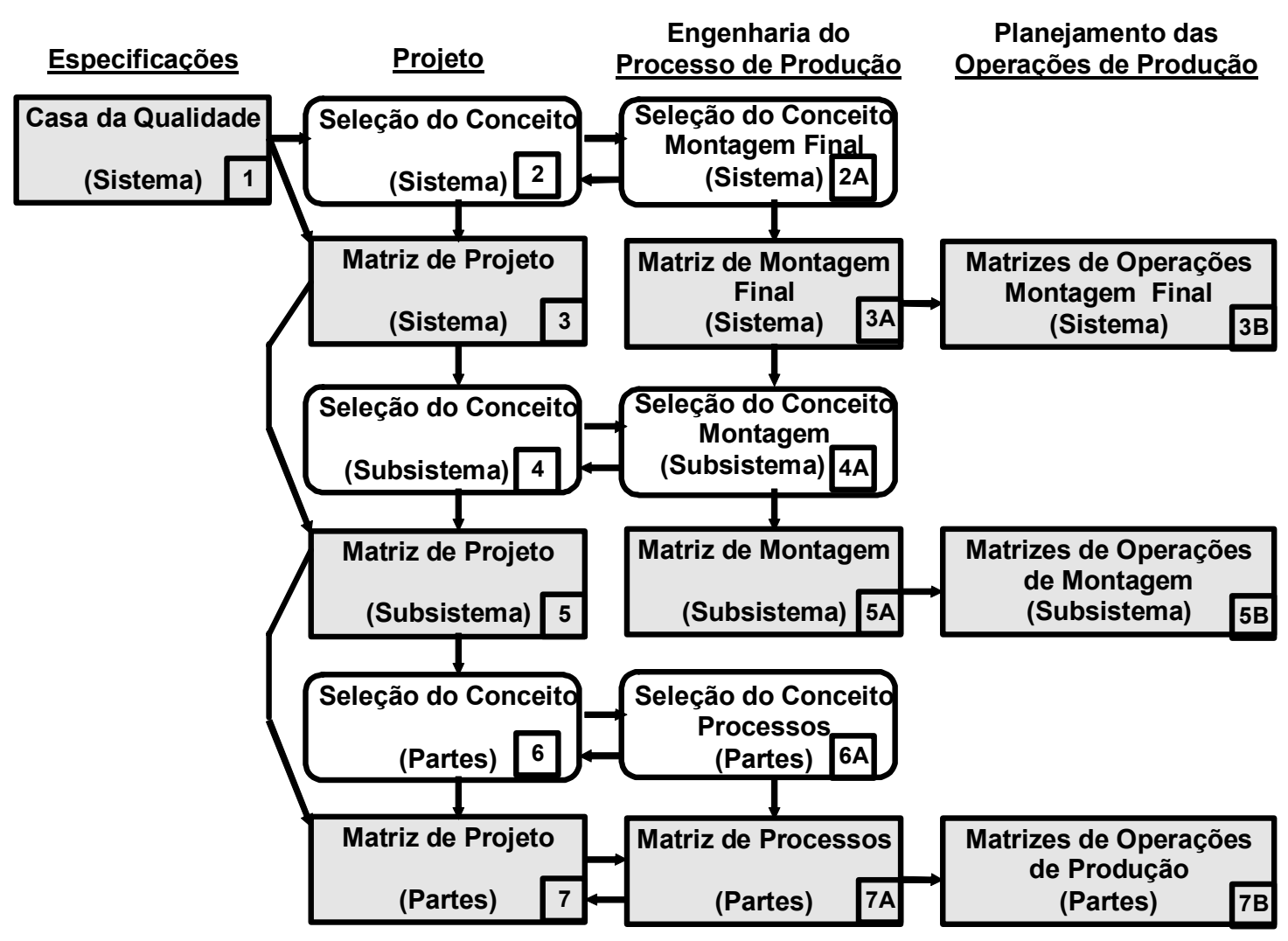

Figura 1: QFD Estendido (Clausing, Pugh, 1991) apud (Carvalho, 1997)

Existem diversos modelos propostos para o QFD (Gustin, 2000), o modelo do American Supplier Instituto (ASI) é o mais simples e popular, restringindo-se ao 
desdobramento da qualidade. É importante ressaltar que nesse artigo pretende-se apresentar a primeira matriz do desdobramento da função qualidade, denominada por Hauser; Clausing (1988), como Casa da Qualidade (HoQ). Sabendo que este trabalho aplica-se a priorização de requisitos de aplicações para EAD, optou-se pelo modelo de QFD estendido, uma vez que se acredita tratar de um desenvolvimento dinâmico, cujo conceito ainda deve ser gerado (Pugh et al., 1996)

O modelo proposto por Clausing; Pugh (1991) apud Carvalho (1997) integra ao modelo das quatro matrizes, do ASI, o processo de seleção de conceitos proposto por Pugh. Segundo Carvalho (1997), este modelo integra as quatro matrizes do modelo tradicional ((HoQ), desdobramento das partes, processos críticos e requisitos de produção) a matrizes de seleção de conceitos, conforme ilustra a Figura 1.

Neste modelo, a seleção de conceitos é feita em múltiplos níveis. Pode-se observar que o modelo das quatro matrizes é repetido três vezes, sempre intercalado pelo processo de seleção de conceitos de PUGH, para produto e processo. Este processo deve partir da arquitetura do sistema total a ser desdobrado em subsistemas, componentes e partes.

O processo de seleção de conceitos proposto por Pugh (1996), apud Carvalho (1997), pode ser visualizado através de uma matriz cujas linhas são os critérios para seleção e as colunas são os conceitos. Um dos conceitos é adotado como base para a comparação e sinais “+”, “-” e “|” são utilizados para representar se um determinado conceito é melhor, pior ou igual, respectivamente, para um determinado critério.

O EQFD é utilizado quando o projeto a ser desenvolvido é de cunho dinâmico. Segundo Pugh et al (1996), no desenvolvimento dinâmico ainda não existe um conceito definido e, portanto, é preciso selecionar aquele que melhor traduza as especificações a serem atendidas. 


\section{UTILIZAÇÃO DO QFD (foco casa da qualidade) E DO EQFD EM UM AMBIENTE DE GERENCIAMENTO DE INFORMAÇÕES PARA ENSINO A DISTÂNCIA: UM ESTUDO DE CASO}

Este trabalho pretende analisar um processo de seleção de conceitos de um sistema para EAD utilizando EQFD e QFD (foco casa da qualidade). Para este fim, optou-se pela abordagem de estudo de caso que permitiria analisar em maior profundidade as questões centrais deste trabalho (Yin, 1991; Claver et al., 2000). O estudo de caso foi desenvolvido no laboratório de ensino a distância do Instituto Municipal de Ensino Superior de Assis LEAD IMESA.

Conforme citado anteriormente, o QFD é um modelo que expressa as necessidades explicitas e implícitas dos clientes. Em ambiente de gerenciamento para EAD tais clientes são caracterizados neste caso por alunos e professores.

Os ambientes de gerenciamento para EAD estão em constante evolução, com isso se faz necessário utilizar o processo de seleção de conceitos abordados na seção 4 (vide Tabela 1). A matriz de seleção de conceitos para EAD foi desenvolvida pela equipe de projeto (professores do LEAD - IMESA).

Por meio da Tabela 1 verifica-se que os conceitos "ferramenta de autoria" e "formas de comunicação" possuem uma maior relevância, com isso, pode-se concluir que esses devem ser tratados com maior atenção no desenvolvimento do ambiente.

Verificadas os conceitos relevantes para a construção de um ambiente de gerenciamento para EAD, se faz necessários levantar quais são as necessidades explicitas e implícitas de alunos e professores no contexto de EAD. Para o levantamento destas necessidades foi aplicada uma pesquisa com 27 questões fechadas. As questões utilizadas no desenvolvimento da pesquisa foram baseadas nos recursos que os ambientes Aulanet (AulaNet, 2001), Learning Space (Lótus, 2001), WebCT (WCT, 2001) e o TelEduc (TeleEduc, 2001) possuem e na matriz de seleção de conceitos (Tabela 1). 
Na pesquisa foi utilizada a escala likert (5 - muito importante, 4 -importante, 3 importância média, 2 - pouco importante e 1 - muito pouco importante) para balizamento dos resultados. Esta pesquisa foi realizada com professores e alunos IMESA.

Tabela 1: Matriz de Seleção de Conceitos para EAD

\begin{tabular}{|c|c|c|c|c|c|}
\hline & \multicolumn{5}{|c|}{ Conceitos } \\
\hline Eritérios & 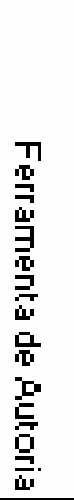 & 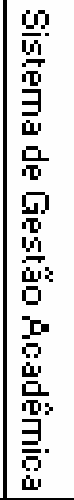 & 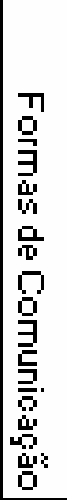 & 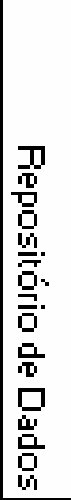 & 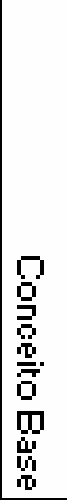 \\
\hline Aualiacẵo do Áluno [Froug] & - & - & - & - & \\
\hline Presenga do Aluno no Ambiente & - & - & - & - & \\
\hline Frequência na Troce de lnitormagốes & - & - & + & - & 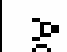 \\
\hline Ferfil do Álıno & 1 & - & - & - & 8 \\
\hline Estrutura para Disponibilizar Aulas & + & 1 & I & 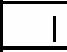 & 营 \\
\hline Acervo Bibliogr f́fico Digital & + & 1 & I & 1 & $\stackrel{ }{\stackrel{7}{*}}$ \\
\hline Perguntas Mais Frequentes & + & - & - & 1 & $\stackrel{\Delta}{\vec{\exists}}$ \\
\hline Adaptabilidade do Material ao Ferfil do Aluno & + & - & - & - & $\stackrel{\mathrm{g}}{g}$ \\
\hline Controle de Notas & - & + & - & - & 9 \\
\hline Matricula Dn-Line & 1 & + & 1 & I & \\
\hline Comunicaģăg Sinerona & - & - & + & - & 목 \\
\hline Eomunicas:äo Assincrona & - & - & + & - & \\
\hline Fepositório de Cursos na 'w'EB & 1 & - & + & + & \\
\hline Fepositório de Cursos em C: FIDM & I & - & + & + & \\
\hline
\end{tabular}

Tabela 2 - Levantamento de Requisitos e Tabulação dos Dados (grau de importância)

\begin{tabular}{|c|c|c|c|c|c|}
\hline \multirow[t]{2}{*}{$\mathbf{N}^{\circ}$ e Requisito } & \multicolumn{5}{|c|}{ Valores Expressos em \% } \\
\hline & 5 & 4 & 3 & 2 & 1 \\
\hline 1..Comunicação Interativa entre professor e aluno. & 80,00 & 4,44 & 13,33 & 2,22 & 0,00 \\
\hline 2. Lista de discussão. & 44,44 & 22,22 & 26,67 & 2,22 & $\overline{4,44}$ \\
\hline 3. Chat (Sala de discussão). & 40,00 & 20,00 & 26,67 & 8,89 & 4,44 \\
\hline 4. Vídeo Conferência. & 53,33 & 28,89 & 6,67 & 8,89 & 2,22 \\
\hline 5. Áudio Conferência. & 35,56 & 20,00 & 20,00 & 11,11 & 13,33 \\
\hline $\begin{array}{l}\text { 6. Agenda ou Mural eletrônico (onde o aluno pode deixar as informações e } \\
\text { recados). }\end{array}$ & 11,11 & 28,89 & 31,11 & 17,78 & 11,11 \\
\hline $\begin{array}{l}\text { 7. Sistema periódico de avaliação eletrônica do aluno (questionário no formato } \\
\text { múltipla escolha). }\end{array}$ & 31,11 & 31,11 & 15,56 & 11,11 & 11,11 \\
\hline 8. Sistema periódico de avaliação eletrônica do aluno (questões dissertativas). & 33,33 & 33,33 & 15,56 & 6,67 & 11,11 \\
\hline
\end{tabular}




\begin{tabular}{|c|c|c|c|c|c|}
\hline 9. Matrículas on-line. & 44,44 & 20,00 & 17,78 & 11,11 & 6,67 \\
\hline 10. Estrutura para disponibilizar planos de aula. & 31,11 & 31,11 & 22,22 & 6,67 & 8,89 \\
\hline $\begin{array}{l}\text { 11. Estrutura para disponibilizar apresentações, textos para estudo, } \\
\text { demonstrações. }\end{array}$ & 44,44 & 48,89 & 2,22 & 4,44 & 0,00 \\
\hline 12. Estrutura para disponibilizar tutoriais (sobre o conteúdo) na Internet. & 28,89 & 46,67 & 13,33 & 6,67 & 4,44 \\
\hline $\begin{array}{l}\text { 13. Estrutura para disponibilizar ferramentas de busca (ex. yahoo, altavista, } \\
\text { google etc.). }\end{array}$ & 26,67 & 20,00 & 24,44 & 13,33 & 15,56 \\
\hline $\begin{array}{l}\text { 14. Ferramenta de busca específica (busca alguma palavra chave de seu } \\
\text { conteúdo). }\end{array}$ & 24,44 & 33,33 & 22,22 & 20,00 & 0,00 \\
\hline 15. Possibilidade dos alunos construirem suas home-pages. & 20,00 & 28,89 & 13,33 & 22,22 & 15,56 \\
\hline $\begin{array}{l}\text { 16. Glossário ou dicionário on-line (sobre os termos técnicos do curso em } \\
\text { questão). }\end{array}$ & 46,67 & 17,78 & 17,78 & 13,33 & 4,44 \\
\hline $\begin{array}{l}\text { 17. Biblioteca do curso (contendo material de referência como artigos, imagens, } \\
\text { arquivos de som, vídeo, links, entre outros). }\end{array}$ & 82,22 & 8,89 & 6,67 & 0,00 & 2,22 \\
\hline $\begin{array}{l}\text { 18. Perfis, identificados pela apresentação do aluno através de dados pessoais, } \\
\text { como fotografia, experiência profissional, formação acadêmica, e-mail, } \\
\text { passatempos, interesse e apelidos. }\end{array}$ & 24,44 & 22,22 & 31,11 & 11,11 & 11,11 \\
\hline 19. Caderno on-line, utilizado para anotações do aluno. & 26,67 & 22,22 & 26,67 & 17,78 & 6,67 \\
\hline 20. Ferramenta para o acompanhamento de progresso do aluno. & 51,11 & 28,89 & 15,56 & 2,22 & 2,22 \\
\hline 21. Disponibilizar perguntas mais freqüentes (FAQs). & 37,78 & 28,89 & 13,33 & 15,56 & 4,44 \\
\hline 22. Possibilidade de adaptar o material ao progresso e ao perfil do aluno. & 35,56 & 35,56 & 20,00 & 8,89 & 0,00 \\
\hline 23 Velocidade de acesso ao conteúdo. & 75,56 & 15,56 & 6,67 & 0,00 & 2,22 \\
\hline $\begin{array}{l}\text { 24. Utilização de outras mídias de transmissão (ex: CD-ROM, Fita K-7, Fita de } \\
\text { Vídeo). }\end{array}$ & 44,44 & 28,89 & 22,22 & 4,44 & 0,00 \\
\hline 25. Parte do curso em CD-ROM e parte na Internet. & 35,56 & 35,56 & 17,78 & 2,22 & 8,89 \\
\hline 26. Ferramenta de administração acadêmica (exemplo: controle de notas). & 28,89 & 35,56 & 15,56 & 8,89 & 11,11 \\
\hline 27. Ambiente de Realidade Virtual (virtualização de pontos importante do curso). & 37,78 & 24,44 & 22,22 & 8,89 & 6,67 \\
\hline
\end{tabular}

O IMESA possui nove cursos de graduação na área de ciências exatas e humanas, cerca de 70 professores e 1200 alunos. A pesquisa contemplou 26 alunos da área de exatas e 19 professores da área de exatas e humanas.

A pesquisa foi coordenada pelo LEAD do IMESA, este laboratório é composto por professores e alunos do curso de Bacharelado em Ciência da Computação. O LEAD busca soluções para a utilização de métodos formais e inteligência artificial aplicados à área de ensino a distância. Dentre os trabalhos que estão sendo desenvolvidos, é proposta uma metodologia para desenvolvimento de um Ambiente de Gerenciamento Inteligente para Ensino a Distância Fabri et. al. (2000) e Fabri et. al. (2002).

A primeira coluna da Tabela 2 apresenta as questões abordadas na pesquisa. As demais colunas relacionam-se com o grau de importância informado por alunos e professores. 
Tabela 3: Balizamento do Questionário Aplicado ao Concorrente $X$ (N.S. representa o nível de satisfação do clientes)

\begin{tabular}{|c|c|c|c|c|c|c|}
\hline Questões & N.S. & $\begin{array}{r}\text { Muito } \\
\text { Satisfeito }\end{array}$ & Satisfeito & $\begin{array}{r}\text { Satisfação } \\
\text { Média }\end{array}$ & $\begin{array}{r}\text { Pouco } \\
\text { Satisfeito } \\
\end{array}$ & $\begin{array}{r}\text { Nada } \\
\text { Satisfeito } \\
\end{array}$ \\
\hline 1 Lista de discussão. & 5 & 25,00 & 58,33 & 16,67 & 0,00 & 0,00 \\
\hline 2 Matrículas on-line. & 5 & 75,00 & 16,67 & 8,33 & 0,00 & 0,00 \\
\hline $\begin{array}{l}3 \text { Glossário ou dicionário on-line (sobre os termos técnicos do } \\
\text { curso em questão). }\end{array}$ & 5 & 44,44 & 55,56 & 0,00 & 0,00 & 0,00 \\
\hline $\begin{array}{l}4 \text { Perfis, identificados pela apresentação do aluno através de } \\
\text { dados pessoais, como fotografia, experiência profissional, } \\
\text { formação acadêmica, e-mail, passatempos, interesse e apelidos. }\end{array}$ & 5 & 8,33 & 75,00 & 8,33 & 8,33 & 0,00 \\
\hline 5 Ferramenta para o acompanhamento de progresso do aluno. & 5 & 54,55 & 36,36 & 0,00 & 0,00 & 9,09 \\
\hline 6 Disponibilizar perguntas mais freqüentes (FAQs). & 5 & 45,45 & 36,36 & 18,18 & 0,00 & 0,00 \\
\hline
\end{tabular}

Além das questões apresentadas na Tabela 2 foram aplicados 2 questionários que procuraram identificar a satisfação dos alunos em relação a outros 2 ambientes para o gerenciamento de informações para EAD, denominados a partir deste momento de concorrentes (vide Tabela 3 e Tabela 4).

Verifica-se que os concorrentes não possuem todos os requisitos presentes na Tabela 2 , isto ocorre porque os requisitos apresentados na Tabela 2 foram baseados na soma de recursos ambientes Aulanet, WebCt, Learning Space e TelEduc. É importante citar que os concorrentes não fazem parte do conjunto de ambientes apresentados. Esta pesquisa levou em consideração somente os ambientes webaula (www.webaula.com.br) e estude grátis (www.estudegratis.com.br).

O balizamento da satisfação dos requisitos para os concorrentes $X$ e $Y$ foi feito por meio da escala likert (muito satisfeito, satisfeito, satisfação média, pouco satisfeito, nada satisfeito) (vide Tabela 3 e Tabela 4). Foram aplicados em torno de 10 questionários tanto para o concorrente $X$ como para o concorrente $Y$, estes questionários foram respondidos somente pelos alunos do curso de Bacharelado em Ciência da Computação. Todos os alunos que responderam aos questionários para os concorrentes $X$ e $Y$ participaram da primeira etapa da pesquisa (classificação sobre a importância dos requisitos presentes na Tabela 2). 
Tabela 4: Balizamento Questionário Aplicado ao Concorrente $Y$ (N.S. representa o nível de satisfação do clientes)

\begin{tabular}{|c|c|c|c|c|c|c|}
\hline Questões & N.S. & $\begin{array}{r}\text { Muito } \\
\text { Satisfeito }\end{array}$ & Satisfeito & $\begin{array}{r}\text { Satisfação } \\
\text { Média }\end{array}$ & $\begin{array}{r}\text { Pouco } \\
\text { Satisfeito }\end{array}$ & $\begin{array}{r}\text { Nada } \\
\text { Satisfeito }\end{array}$ \\
\hline 1 Lista de discussão. & 1 & 30,00 & 20,00 & 20,00 & 10,00 & 20,00 \\
\hline 2 Chat & 1 & 30,00 & 20,00 & 20,00 & 10,00 & 20,00 \\
\hline $\begin{array}{l}3 \text { Sistema de Avaliação Eletrônica do Aluno (questões no } \\
\text { formato multipla escolha) }\end{array}$ & 2 & 50,00 & 10,00 & 30,00 & 10,00 & 0,00 \\
\hline 4 Matrículas on-line. & 5 & 80,00 & 20,00 & 0,00 & 0,00 & 0,00 \\
\hline $\begin{array}{l}5 \text { Ferramenta de busca específica (busca alguma palavra chave } \\
\text { de seu conteúdo) }\end{array}$ & 5 & 70,00 & 30,00 & 0,00 & 0,00 & 0,00 \\
\hline $\begin{array}{l}6 \text { Perfis, identificados pela apresentação do aluno através de } \\
\text { dados pessoais, como fotografia, experiência profissional, } \\
\text { formação acadêmica, e-mail, passatempos, interesse e apelidos. }\end{array}$ & 5 & 40,00 & 20,00 & 20,00 & 0,00 & 20,00 \\
\hline 7 Ferramenta para o acompanhamento de progresso do aluno. & 4 & 33,33 & 44,44 & 22,22 & 0,00 & 0,00 \\
\hline 8 Disponibilizar perguntas mais freqüentes (FAQs). & 5 & 30,00 & 20,00 & 50,00 & 0,00 & 0,00 \\
\hline
\end{tabular}

\section{Analise dos Resultados e a Construção da Casa da Qualidade}

Por meio do balizamento dos resultados verifica-se que: para o levantamento de requisitos e a classificação em relação a sua importância 26 questionários foram respondidos por alunos $(57,78 \%)$ e 19 por professores $(42,22 \%)$. O LEAD optou por coletar o ponto de vista dos professores de duas áreas: exatas $(9$, totalizando $47,37 \%)$ e humanas (10, totalizando $52,63 \%)$.

Por meio da Tabela 2, verificam-se que $80 \%$ dos entrevistados concluem que é muito importante que o ambiente forneça comunicação interativa entre o professor e o aluno (questão 1). As questões 2 (lista de discussão), 3 (chat), 4 (vídeo conferência), 5 (aúdio conferência) e 6 (mural eletrônico) relacionam-se diretamente a questão 1. Nestas questões verifica-se que a soma do aspecto muito importante com importante resulta em $66,44 \%$; 60\%; $87,22 \% ; 55,56 \%$ e $40 \%$ para as questões $2,3,4,5$ e 6 respectivamente. Com isto pode-se afirmar que a idéia de interação com vídeo conferência prevalece na pesquisa. Porém, a questão 6 (mural eletrônico) já não representa grande importância na pesquisa. 
Por meio destes resultados os professores que compõem o LEAD enumeraram as primeiras característica da qualidade (interação síncrona e assíncrona), estas irão fazer parte da casa da qualidade.

Partindo para a questão 7 (sistema periódico da avaliação do aluno (múltipla escolha)) verifica-se que cerca de $31,11 \%$ dos alunos e professores consideram a tal questão muito importante e $31,11 \%$ importante (totalizando $62,22 \%$ ). Já para a questão 8 , que trata de avaliação dissertativa, o índice sobe um pouco, 33,33 consideram-na muito importante e uma mesma fatia importante (totalizando 66,66\%). Esta duas questões estão relacionadas as questões 18 (ferramenta para acompanhamento de progresso do aluno). O índice muito importante de tal questão ultrapassa os $50 \%$. A avaliação pode ser um método para este acompanhamento. Tal acompanhamento pode ser feito de forma automática (Fabri et. al., 2002) pelo ambiente, por exemplo: o aluno ao final de cada módulo realiza uma prova com questões múltiplas escolha, e automaticamente o sistema corrige tal prova e envia o resultado (nota) para o aluno e professor. Em questões dissertativas esta automatização fica complicada, pois para obter resultados satisfatórios com este tipo de processo, o ambiente deve implementar técnicas de processamento de linguagem natural.

Com base nestes resultados os professores do LEAD optaram por enumerar mais uma característica da qualidade, o acompanhamento do aluno.

As questões de 10 a 17 estão relacionadas à idéia de autoria (Tatizana, 1999). Verifica-se que o requisito biblioteca do curso (questão 17) é de extrema importância com 82,22\% para muito importante. Seguido de glossário on-line (questão 16) com 46,67\% para muito importante. Destaca-se como requisito primordial a idéia de disponibilizar apresentações e textos para estudos (questão 11), 93,33 indicam que tal requisito é importante ou muito importante. Um dado interessante é que $100 \%$ dos professores classificaram este recurso como muito importante e importante. Por meio destes índices conclui-se que os 
professores estão conscientes que iram atuar diretamente com o ambiente de gerenciamento para ensino a distância. Tais índices levaram os professores do LEAD a idealizar outra característica da qualidade, ferramenta de autoria.

O requisito perfil do aluno (questão 18) não é considerado importante por parte dos entrevistados. Porém o requisito possibilidade de adaptar o material ao perfil aluno possui um índice de 35,56\% para muito importante e a mesma fatia para importante. Com isso pode-se afirmar que existe um certo grau de incoerência nas respostas dos entrevistados, pois não é possível adaptar o material ao perfil do aluno sem que este perfil não esteja armazenado no ambiente. Os professores do LEAD optaram por definir a adaptação do material ao perfil do aluno como uma das características da casa da qualidade.

A questão 23 (velocidade de acesso) pode ser comparada às questões 24 (utilização de outras mídias de transmissão) e 25 (parte do curso em CD-ROM). Mais de $75 \%$ dos entrevistados disseram que a velocidade de acesso é muito importante, $73,33 \%$ classificaram a utilização de outras mídias como muito importante ou importante e 71,12\% dos entrevistados admitiram a possibilidade do curso ser parte em CD ROM e parte na Internet. Por meio destes índices conclui-se, que os entrevistados têm consciência que a Internet não satisfaz, totalmente, o requisito velocidade de acesso, provando assim que este meio, ainda, é lento para os usuários domésticos. Estes índices resultaram em três características da qualidade: velocidade de acesso, formas de acesso ao conteúdo (acesso via CD ROM ou Internet) e repositório de mídia (outras mídias onde os conteúdos das aulas podem ser armazenados).

Uma última característica de qualidade que a equipe do LEAD optou por enumerar foi o sistema de administração acadêmico.

Com estes dados é possível apresentar, graficamente, alguns "cômodos" da casa da qualidade: requisitos dos clientes (professores e alunos), grau de importância, características 
da qualidade, relação entres os requisitos dos clientes e as características da qualidade e a correlação entre os requisitos da qualidade (Figura 2).

Os professores do LEAD optaram por enumerar 21 requisitos de alunos e professores (vide Figura 2).

Na Tabela 2 é responsável por quantificar o grau de importância da casa da qualidade. Este grau é quantificado por meio de uma escalada apresentada na Tabela 5. Verifica-se por meio da Tabela 5 que é atribuído grau 5 quando a soma do aspecto importante e muito importante ultrapassam $80 \%$. O mapeamento destes valores foi definido pela equipe do LEAD.

Tabela 5 - Escala para o mapeamento do grau de importância

\begin{tabular}{|l|l|}
\hline Escala & $\%$ soma (muito importante, importante) \\
\hline 1 & $<=50 \%$ \\
\hline 2 & $51-60 \%$ \\
\hline 3 & $61-70 \%$ \\
\hline 4 & $71-80 \%$ \\
\hline 5 & $>80 \%$ \\
\hline
\end{tabular}

A relação entre os requisitos dos clientes e as características da qualidade podem ser visualizadas por meio da Figura 2. Verifica-se que os relacionamentos foram quantificados em forte ( 9 pontos), moderado ( 3 pontos) e fraco ( 1 ponto). Este relacionamento é definido pela equipe responsável pelo o desenvolvimento dos projetos, neste caso os professores do LEAD do IMESA.

A correlação entre as características de qualidade representa o telhado da casa da qualidade, esta correlação é definida como forte, fraca e moderada, os símbolos para tais valores podem ser vistos na Figura 2. Por meio do telhado da casa da qualidade pode-se dizer, por exemplo, que a características de comunicação assíncrona tem correlação forte com a característica velocidade de acesso. 
Figura 2: Casa da Qualidade para EAD

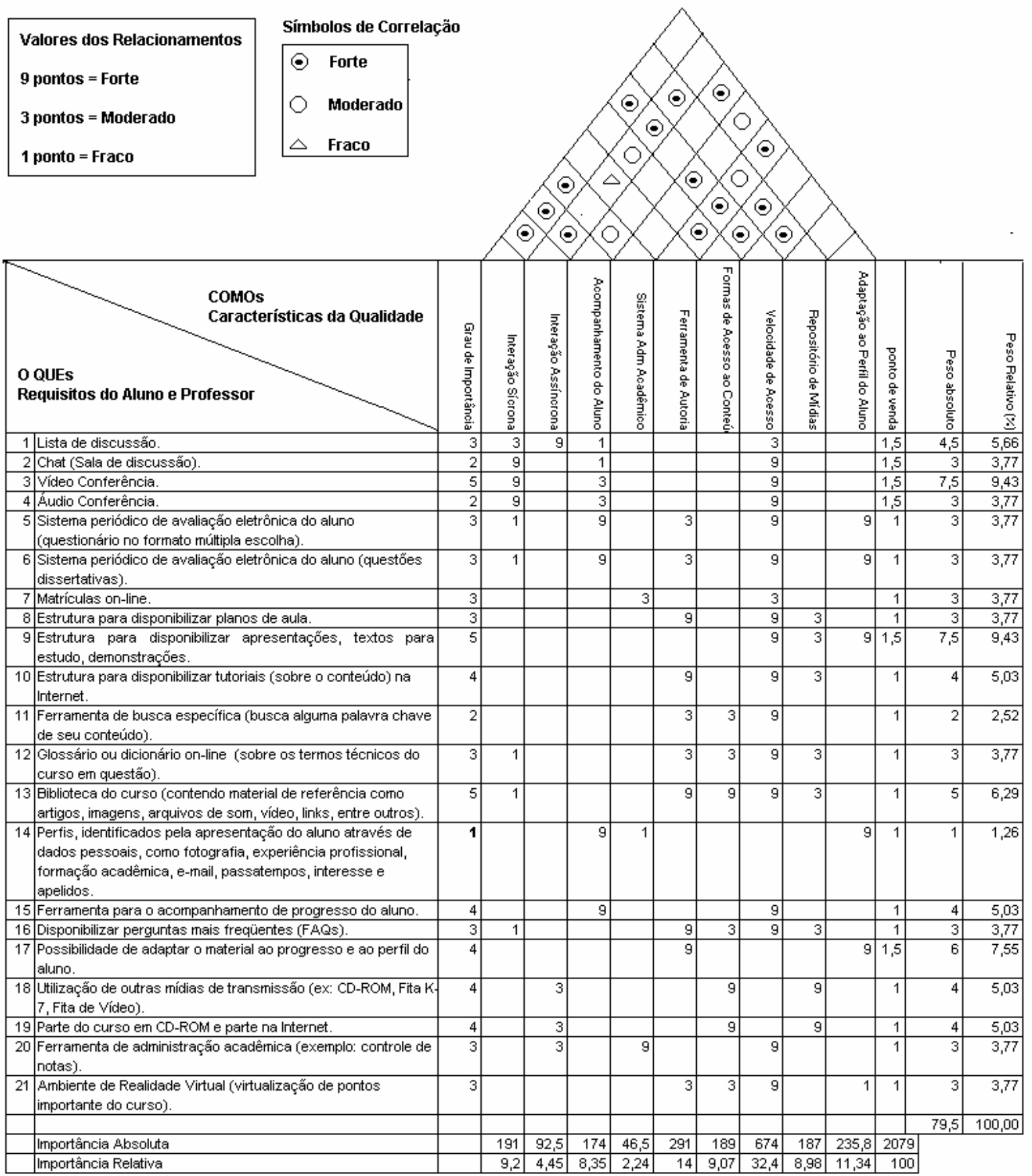

Após a definição dos requisitos do cliente, grau de importância, características da qualidade, relacionamento entre os requisitos do cliente e características da qualidade e correlação entre as características, será ilustrada a satisfação do cliente em relação aos concorrentes $X$ e $Y$. 
Conforme ilustrados na seção anterior, os concorrentes não possuem todas os requisitos enumerados na casa da qualidade. Por meio disto, o balizamento das informações dos concorrentes foram ilustrados a parte na Tabela 3 e Tabela 4 . O nível de satisfação é obtido por meio de uma escala ilustrada na Tabela 5.

Na Figura 2 verifica-se a presença da coluna ponto de venda, este item faz parte na análise competitiva externa. O ponto de venda traduz os requisitos considerados importantes para a empresa e podem receber os valores 1.0 requisitos que não são considerados pontos de venda, 1.2 considerados pontos de venda e 1.5 para fortes pontos de venda. Este valores foram atribuídos pelos professores responsáveis pelo LEAD.

O valor do peso absoluto é calculado pela seguinte equação: $w_{i}=g_{i} t_{i} v_{i}$

onde $w_{i}$ representa o peso absoluto para o requisito do consumidor $\left(r c_{i}\right) ; g_{i}$ grau de importância para $r c_{i} ; t_{i}$ taxa de melhoria para o $r c_{i}$ e $v_{i}$ valor do ponto de venda para $r c_{i}$.

Neste trabalho não é contemplado a taxa de melhoria $(t)$. Com isso o calculo do peso absoluto pode ser obtido por meio da seguinte equação: $w_{i}=g_{i} v_{i}$

Após calcular o peso absoluto, pode-se obter o peso relativo (tal peso indica o percentual para cada peso absoluto) por meio da seguinte equação:

$$
w_{i}^{\%}=w_{i} \cdot 100 / \sum_{i=1}^{n} w_{i}
$$

onde $w_{i}^{\%}$ representa o peso relativo para $r c_{\mathrm{i}}$ e $i=1$ a $n$.

Com base na matriz de relacionamentos e no peso relativo dos requisitos do consumidor, é possível estabelecer um peso absoluto e relativo das características da qualidade, veja as equações abaixo:

$$
w c_{i}=\sum_{i}^{m} r_{i j} \cdot w_{i}^{\%}
$$

onde $w c_{i}$ é o peso absoluto da características da qualidade $\left(c q_{i}\right) ; r_{i j}$ relacionamento do $r c_{\mathrm{i}}$ e da $c q_{\mathrm{i}}$ e $i=1$ a $m$ e $j=1$ a $n$. 


$$
w c_{j}^{\%}=w c_{j} .100 / \sum_{j=1}^{n} w_{i}
$$

em que $w c_{j}^{\%}$ representa o peso relativo da $c q_{\mathrm{j}}$

Os cálculos resultantes das equações podem ser vistos Figura 2.

Após a obtenção da casa de qualidade é necessário realizar a analise dos resultados obtidos, e verificar quais as diretrizes deve-se percorrer para se obter um ambiente de gerenciamento de informações para ensino a distância de acordo com as necessidades de alunos e professores.

\section{INTERPRETAÇÃO DA CASA DA QUALIDADE}

Analisando a casa da qualidade Figura 2 verifica-se que: Os requisitos vídeo conferência $(9,43 \%)$, estrutura para disponibilizar apresentações, textos para estudos e demonstrações $(9,43 \%)$, possibilidade para adaptar o material ao progresso do aluno $(7,55 \%)$ e biblioteca do curso (6,29\%), possuem um peso maior para professores e alunos. As características de qualidade velocidade de acesso (32,4\%), ferramenta de autoria $(14 \%)$ e adaptação ao perfil $(11,34 \%)$ do aluno são as características que receberam maior importância.

Por meio destes dados verifica-se que estes requisitos devem ser implementados com um maior cuidado em um ambiente de gerenciamento para ensino a distância, complementando os conceitos extraídos da matriz de seleção apresentada na seção 5 (Tabela 1).

Cabe ressaltar neste trabalho uma certa insegurança de alunos e professores em relação ao tema ensino a distância. Verifica-se que um dos requisitos mais importantes referese a vídeo conferência. Analisando os conceitos de EAD percebe-se que o EAD ocorre quando aluno e professores estão separados no tempo e no espaço. Em um sistema de ensino 
por vídeo conferência o fator tempo do conceito de EAD não é considerado, descaracterizando a idéia de EAD. Porém não faz sentido em abrir mão, totalmente, deste recurso, pois o mesmo pode ser utilizado para uma aproximação maior de alunos e professores. A vídeo conferência em um ambiente de EAD deve ser utilizada periodicamente para o professor orientar um grupo de alunos.

A disponibilização e adaptação do conteúdo ao perfil do aluno completam as maiores necessidades apontadas pela casa da qualidade. Isto mostra que o conteúdo deve ser dinâmico e adaptativo. Um ambiente que preze a qualidade deve promover em sua estrutura conteúdos com tais características, e dar a possibilidade ao autor da aula (professor) para que estas sejam contempladas no momento de inserção da aula.

Um dos valores que chama a atenção na casa da qualidade é o de $32,4 \%$ de importância para a característica da qualidade velocidade de acesso. Esta característica possui um forte relacionamento com maior parte dos requisitos e com a maioria das características da qualidade, sendo considerada de primordial importância no desenvolvimento de qualquer ambiente de gerenciamento.

\section{CONCLUSÕES}

Este trabalho analisou a viabilidade da utilização do EQFD no desenvolvimento de ambientes de gerenciamento de informações para EAD. Em sua estrutura foi contemplado definição do time de gerenciamento de projeto, levantamento dos requisitos tecnológicos; classificação dos requisitos para construção da "Casa de Qualidade", segundo peso relativo proposto no QFD.

Por meio deste trabalho, pôde-se verificar que o QFD e o EQFD podem ser utilizados como uma ferramenta para a definição e priorização de requisitos para ambientes de EAD. Acredita-se que com QFD e EQFD os professores do LEAD conseguiram mapear a voz do 
consumidor (professores e alunos) com um certo grau confiável. Porém a utilização do QFD e do EQFD deve ser realizada constantemente durante o processo de desenvolvimento de um ambiente de gerenciamento de informações para EAD.

A característica da qualidade velocidade de acesso obteve um alto grau de importância na casa da qualidade, mostrando assim que um ambiente voltado totalmente à Internet possui uma certa insatisfação de professores e alunos, isto ocorre devido a baixa velocidade de comunicação presente na Internet.

A preocupação de alunos e professores em relação a disponibilização e adaptação de conteúdo foram mapeadas de forma clara pela casa da qualidade.

Parte da equipe multidisciplinar, o tempo de projeto, custos e riscos para o desenvolvimento deste ambiente não são contemplados neste trabalho.

Como recursos de tecnologia da informação a equipe do LEAD vislumbra que o ambiente deva possuir: servidores, equipamento para gerência de vídeo e áudio conferência, roteadores, switch, hubs, câmeras de vídeo digitais, sistema de gerenciamento banco de dados, sistemas operacionais, software voltados para o gerenciamento de redes, softwares colaborativos, softwares aplicativos, etc.

Um dos pontos fracos deste trabalho foi a impossibilidade de se obter a avaliação competitiva do cliente. A tentativa de comparar a idéia do ambiente de gerenciamento de informações para EAD à ambientes freeware que possuem o mesmo contexto, contribuiu para este fator.

Com o avanço no desenvolvimento do ambiente de gerenciamento de informações para EAD, o LEAD deve desenvolver uma nova pesquisa utilizando o QFD e EQFD utilizando a avaliação comparativa inerente ao QFD. Como concorrentes o LEAD deve utilizar os ambientes Aulanet, Learning Space, TelEduc, e WebCT. 
Muitas contribuições devem ser dadas para a definição de padrões de qualidade para ambientes de gerenciamento de informações para EAD. Por fim este trabalho buscou a voz dos clientes (professores e alunos) para a definição de requisitos e características de qualidade para tais ambientes.

\section{REFERENCIAS}

AKAO, Y. Quality Function Deployment: Integrating Customer Requirements into Product Desing. Cambridge, Massachusetts: Productivity Press, 1990.

CARVALHO, M. M. QFD: Uma Ferramenta de Tomada de Decisão em Projeto. Florianópolis, 1997. Tese (Doutorado) Departamento de Engenharia de Produção e Sistemas. Universidade Federal de Santa Catarina

CARVALHO. M.M Qualidade em Projetos. In AMATO. Manufatura Classe Mundial . São Paulo Editora Atlas, 2001

CARVALHO. M.M. Selecionando Projetos Seis Sigma. In RONTONDARO. Seis Sigma . São Paulo Editora Atlas, 2002

CHAVES. E. Ensino a Distância Conceitos Básicos. Disponível em $<$ http://www.edutecnet.com.br/>. Acesso em 10 de fevereiro de 1999.

CLAUSING, D. Total Quality Development a Step by Step Guide to World Class Concurrent Engineering. New York, ASME Press 1994

CLAVER, E.; GONZALEZ, R.; LLOPIS, J. An analysis of research in information systems (1981-1997). Information \& Management, v.37, n.4, p.181-195, Apr. 2000.

COHEN, L. Quality Function Deployment: How to Make QDF Work for You. Reading Massachusetts: Addison Wesley, 1995.

Decreto lei 2.494 de 10 de fevereiro de 1998. Disponível em <http://www.mec.gov.br>. Acesso em 10 de maio de 2002.

Estude Gratis. Portal estude gratis. Disponível em <www.estudegratis.com.br> Acesso em: 2000 .

FABRI, José A.; CAMOLESI, Almir R.; FORNAZARI, Fábio P. Uma Metodologia para o Desenvolvimento de um Ambiente de Gerenciamento Inteligente para Ensino a Distância. X Seminário Regional de Informática. Santo Ângelo - RS. 2000. 
FABRI, José A.; CAMOLESI, Almir R.; FORNAZARI, Fábio P.; MACHADO, Osmar.; CUNHA, Douglas S. EAD-IMESA: Um Ambiente de Gerenciamento Inteligente para Ensino a Distância. I Workshop de Informática Aplicada à Educação Universidade de Araraquara (UNIARA) Araraquara - SP. Agosto de 2000.

FABRI, José A.; FABRI, Marília G. S. Ferramenta Fuzzy Para Acompanhamento do Desempenho dos Alunos nos Cursos a Distância. Workshop de Informática na Escola. Florianópolis - SC. 2002.

GUSTIN, G. B; NERY, R. Uso do QFD no Setor de Serviços: Avaliação de uma Transportadora Rodoviária de Carga. Encontro Nacional de Engenharia de Produção. 2000

HAUSER,J.R.; CLAUSING, D. The House of Quality. The Harvard Business Review, v.66, n.3, p.63-73, May/June, 1988.

Laboratório de Engenharia de Software PUC - RJ. O que é o Aulanet. Disponível em $<$ http://anauel.cead.puc-rio.br/aula net/index.html $>$. Acesso em abril de 2001

LOTUS. <Apresentação do Learning Space. Disponível em $<$ http://www.lotus.com/home.nsf/welcome/ learnspace>. Acesso em março de 2001.

MEC. Site de Ministério de Educação e Cultura. Disponível em <http://www.mec.gov.br>. Acesso em 10 de maio de 2002

Núcleo de Informática Aplicada à Educação da Unicamp. Página de Projeto TelEduc. Disponível em http://www.nied.unicamp.br. Acesso em março de 2001.

PMI. Project Management Body of Knowledge. Disponível em <www.pmi.org.br $>$ Acesso em: 2004.

PRESSMAN, R. S. Software Engineering: A Practitioner's Approach. McGraw-Hill 4a. edition, 1997

PUGH, S; CLAUSING, D.; ANDRADE, R. Creating Innovative Products Using Total Design: the living legacy of Stuart Pugh. Editora Addison-Wesley, 1996.

ROSENBERG. M. J. e-Learning: Estratégia para a Transmissão do Conhecimento na Era Digital. São Paulo. Makron Books, 2002.

TATIZANA, Celso. Visual Class Multimídia Software para Criação. Editora Érica. 1999.

WEBAUAL. Portal WebAula Educação sem fronteiras. Disponível em $<$ www.webaula.com.br> Acesso em: 2000. 
WebCT 3.5. Web Course Tool. Disponível em <http://www.webct.com>. Acesso em abril de 2001 .

YIN, R.K. Case Study Research: Design and Methods. Newbury Park, Rev. ed. Sage Publications, 1991.

Artigo recebido em 29/04/05 e aceito para publicação em 13/06/05. 